\title{
Report of the Korean Association of External Quality Assessment Service on Next-Generation Sequencing Analysis for Somatic Variants (2018-2020)
}

\author{
Hongkyung Kim ${ }^{\circledR}$, Dongju Won ${ }^{\circledR}$, Saeam Shin ${ }^{\circledR}$, Seung-Tae Lee ${ }^{\circledR}$, and Jong Rak Choi ${ }^{\circledR}$ \\ Department of Laboratory Medicine, Yonsei University College of Medicine, Seoul, Korea
}

\section{Corresponding author:}

Saeam Shin

Department of Laboratory Medicine, Yonsei University College of Medicine, 50-1 Yonsei-ro, Seodaemun-gu, Seoul 03722, Korea

Tel +82-2-2228-2453

E-mail saeam0304@yuhs.ac

This is an Open Access article distributed under the terms of the Creative Commons Attribution Non-Commercial License (http://creativecommons.org/licenses/ by-nc/4.0) which permits unrestricted non-commercial use, distribution, and reproduction in any medium, provided the original work is properly cited.
Next-generation sequencing is widely used to detect a variety of genetic defects in many disorders. The detection of somatic variants in patients with cancer, including hematologic malignancy, is important for diagnosis, treatment, and prognosis. However, due to the complicated process, accurate and reliable detection of somatic variants by next-generation sequencing remains challenging. We investigated the proficiency tests conducted by the Korean Association of External Quality Assessment Service from 2018 to 2020 and their effects on the analytical performance of clinical laboratories. During the 3-year study period, six rounds of proficiency tests were conducted. In each round, the participating laboratories were required to report Tier I/ II somatic variants detected from electronic data and a DNA specimen. The analytical performance was evaluated by calculating the acceptance rate for each genomic position investigated. The possible causes of 'nonevaluable' and 'unacceptable' variants were also explored. Among the six rounds of proficiency tests, the acceptance rates for all tested variants were above $80 \%$ and acceptance rates of $100 \%$ were identified in more than half of the variants in the target regions. Issues of variant classification and falsenegative variants were addressed through the analysis of 'non-evaluable' variants. The significant causes of 'unacceptable' variants were identified as wrong protein or nucleotide numbering. In conclusion, the proficiency tests demonstrated the good analytical performance of the participating clinical laboratories. Although the findings identified some problems awaiting solutions, the proficiency tests may help clinical laboratories to improve their performance in detecting somatic variants by next-generation sequencing.

(Lab Med Qual Assur 2021;43:65-71)

Key Words Laboratory Proficiency Testing, External quality assurance, Nextgeneration sequencing, Somatic variant

\section{서론}

차세대염기서열분석법(next-generation sequencing, NGS) 는 수백만 개의 염기서열분석을 병렬로 처리하여 광범위한 유전
적 변화를 동시에 검출할 수 있는 방법으로, 다양한 질병의 진단 과 치료, 예후 예측에 활용되고 있다[1]. 국내에서도 NGS를 이용 한 유전자패널검사가 2017년 3월부터 선별급여로 시행됨에 따 라 여러 임상검사실에서 다양한 유전자패널검사가 운영되고 있다. 
유전자패널검사는 질환에 따라 분류될 수 있지만, 분석대상이 생 식세포(germline)인지 체세포(somatic)인지에 따라서도 분류될 수 있고 최근 혈액종양을 포함한 암의 분자적 진단이 중요해짐에 따라 NGS를 이용한 체세포 변이검사의 필요성이 증가되고 있다 [2,3]. 그러나 NGS검사는 빠르게 변화하는 기술을 기반으로 하고 있고 복잡한 검사방법과 분석과정을 통해 시행되므로 잘못된 검 사결과를 보고할 수 있는 잠재성이 존재한다. 그리고 일반적으로 40\%-60\%의 변이 대립유전자 빈도를 보이는 생식세포 변이와는 달리, 체세포 변이의 경우 NGS 검사를 통해 매우 다양한 범위의 대립유전자 빈도가 관찰되는데, 특히 낮은 대립유전자 빈도를 보 이는 경우 검출이 까다로울 수 있다[1,4,5].

신빙도조사는 임상검사실에서 시행되는 검사의 정확도와 신뢰 성을 외부적으로 측정하기 위해 고안된 것으로, 내부정도관리로는 발견하기 어려운 계통오차를 발견하여 검사결과의 정확도를 유지 하기 위한 목적으로 시행된다. NGS를 이용하여 체세포 변이검사 를 시행하는 임상검사실들은 신빙도조사를 통하여 분석결과를 공 유하고 비교함으로써 이들의 검사수행능 향상을 기대할 수 있다. 일반적으로 NGS를 이용한 체세포 돌연변이 평가를 위한 특정 물 질을 확보하기 어려우므로 검사법 기반의 방법을 통해 신뢰도조사 가 시행된다[6].

저자들은 2018년부터 2020년까지 대한임상검사정도관리협회 의 신빙도조사사업으로 실시되었던 NGS-somatic 신빙도조사의 결과를 분석하여 국내에서 시행되는 NGS를 이용한 체세포 변이 분석검사의 현황을 보고하고자 한다.

\section{재료 및 방법}

\section{1. 신빙도조사 분석 자료}

2018년부터 2020년까지 대한임상검사정도관리협회에 의 해 시행된 NGS-somatic 신빙도조사 자료를 사용하였다. NGSsomatic 신빙도조사는 연간 2회 시행되었으며, 회차당 각각 1 개 의 전자데이터(fastq파일 또는 bam파일)와 1 개의 핵산(DNA) 검 체가 사용되었다. 전자데이터는 대한임상검사정도관리협회의 신 빙도조사사업 홈페이지(http://eqas.keqas.org)에서 다운로드 받아 분석하도록 하였으며, 핵산 검체는 해당 임상검사실로 발송 되어 분석되었다.

\section{2. 신빙도조사 평가방법 및 기준}

각 회차별로 분석하는 검체에 대하여 24 개에서 31 개 사이의 검 사대상 유전체 부위가 제시되었다. 전자데이터의 경우 제시된 모 든 유전체 부위에서 결과를 보고하고, 핵산 검체의 경우 제시된 유 전체 부위 중 해당 임상검사실에서 검사를 시행하는 부위에 대해 서만 보고하도록 하였다. 결과 보고는 검사대상 유전체 부위에서 Tier I/II로 평가되는 염기변이의 유무를 확인한 후, 해당 변이가 검출되는 경우 이를 Human Genome Variation Society의 표 준권고안에 따라 기술하도록 하였다. 기술된 변이가 의도된 결과 와 일치하고 참여기관의 $80 \%$ 이상에서 합의(concordance)된 결 론을 보이는 경우 'acceptable'로 평가하였고, 일치하지 않는 경 우 ‘unacceptable’로 평가하였다. 참여기관의 $80 \%$ 미만으로 합

Table 1. Scheme for the proficiency tests for next-generation sequencing of somatic variants during 2018-2020

\begin{tabular}{|c|c|c|c|c|c|c|}
\hline \multirow{2}{*}{ Specimen } & \multirow{2}{*}{ Type } & \multirow{2}{*}{$\begin{array}{c}\text { No. of } \\
\text { participants }\end{array}$} & \multirow{2}{*}{$\begin{array}{l}\text { No. of target } \\
\text { region }\end{array}$} & \multicolumn{3}{|c|}{ Variant type (no.) } \\
\hline & & & & No variant & SNV & INDEL \\
\hline GNS-18-01 & Fastq file & 12 & 30 & 27 & 1 & 2 \\
\hline GNS-18-02 & DNA & 11 & 30 & 28 & 0 & 2 \\
\hline GNS-18-03 & Fastq file & 9 & 30 & 29 & 1 & 0 \\
\hline GNS-18-04 & DNA & 12 & 30 & 28 & 1 & 2 \\
\hline GNS-19-01 & Fastq file & 12 & 31 & 29 & 0 & 2 \\
\hline GNS-19-02 & DNA & 15 & 31 & 29 & 1 & 1 \\
\hline GNS-19-03 & Fastq file & 13 & 31 & 30 & 1 & 0 \\
\hline GNS-19-04 & DNA & 18 & 31 & 30 & 1 & 0 \\
\hline GNS-20-01 & Bam file & 15 & 31 & 29 & 2 & 0 \\
\hline GNS-20-02 & DNA & 21 & 31 & 29 & 2 & 0 \\
\hline GNS-20-03 & Bam file & 17 & 24 & 23 & 1 & 0 \\
\hline GNS-20-04 & DNA & 21 & 24 & 22 & 1 & 1 \\
\hline
\end{tabular}

Abbreviations: SNV, single nucleotide variant; INDEL, insertion/deletion variant. 
의되지 않는 결론을 보이는 변이는 평가에서 제외하였다(nonevaluable).

\section{3. 신빙도조사 결과 분석}

2018년부터 2020년도까지 NGS-somatic 신빙도조사에 참여 한 기관의 수와 신빙도조사에 사용된 검체의 종류, 검사대상 유전 체 부위 및 해당 변이의 형태를 조사하였다. 평가가 시행된 각각의 유전체 부위의 합격률(acceptance rate [\%])을 계산하였으며, 이 때 분모는 해당 유전체 부위에 결과를 제출한 기관의 수로, 분자는 이 중 'acceptable'을 받은 기관의 수로 하여 비율이 산출되었다. 평가에서 제외된 변이와 'unacceptable'로 평가된 변이의 특성 및 빈도를 조사하였다.

\section{결과}

2018년부터 2020년까지 시행된 NGS-somatic 신빙도조사의 참여기관 수, 검체 종류, 검사대상 유전체 부위의 개수 및 변이 유 형을 각 회차별로 정리하였다(Table 1). 참여기관의 수는 각 회차 별로 차이가 있으며, 동일 회차의 검체 및 검사대상 유전체 부위에 따라서도 참여기관의 수가 다른 것이 확인되었다. 참여기관의 수 는 시간이 지남에 따라 점진적으로 증가하는 추세를 보였다. 검체 의 종류는 회차별로 1 개의 전자데이터와 1 개의 핵산 검체가 분석 되었으며, 전자데이터의 경우 2018년 1차 신빙도조사부터 2019 년 2차 신빙도조사까지 fastq file이 이용되었고 2020년 1, 2차 신 빙도조사에서는 bam file이 이용되었다. 검사대상 유전체 부위로 2018년 1, 2차 신빙도조사에서는 30개, 2019년 1차 신빙도조사 부터 2020년 1차 신빙도조사까지 31개, 그리고 2020년 2차 신빙 도조사에서 24 개가 각각 제시되었다. 제시된 검사대상 유전체 부

Table 2. Acceptance rates for the variants of the intended response

\begin{tabular}{|c|c|c|c|c|c|}
\hline \multirow{2}{*}{ Specimen } & \multirow{2}{*}{ Gene } & \multicolumn{3}{|c|}{ Variant of intended response } & \multirow{2}{*}{$\begin{array}{c}\text { Acceptance rate } \\
(\%)\end{array}$} \\
\hline & & Transcript & Nucleotide change & Protein change & \\
\hline \multirow[t]{3}{*}{ GNS-18-01 } & CEBPA & NM_004364.4 & c.430dupG & p.Glu144GlyfsTer26 & 9/10 (90.0) \\
\hline & $I D H 1$ & NM_005896.2 & c. $394 C>G$ & p.Arg132Gly & $12 / 12(100.0)$ \\
\hline & NPM1 & NM_002520.6 & c.860_863dupTCTG & p.Trp288CysfsTer12 & $11 / 12(91.7)$ \\
\hline \multirow[t]{2}{*}{ GNS-18-02 } & CEBPA & NM_004364.4 & c.282_312del & p.Val95ThrfsTer55 & 9/11 (81.8) \\
\hline & $I K Z F 1$ & NM_006060.5 & c.14_17dupAGGG & p.Gln7GlyfsTer21 & 9/10 (90.0) \\
\hline GNS-18-03 & KIT & NM_000222.2 & c. $2447 \mathrm{~A}>\mathrm{T}$ & p.Asp816Val & 9/9 (100.0) \\
\hline \multirow[t]{3}{*}{ GNS-18-04 } & DNMT3A & NM_022552.4 & c. $2645 G>A$ & p.Arg882His & $12 / 12(100.0)$ \\
\hline & FLT3 & NM_004119.2 & c.1784_1804dup & p.Arg595_Leu601dup & $11 / 11(100.0)$ \\
\hline & NPM1 & NM_002520.6 & c.860_863dup & p.Trp288CysfsTer12 & $12 / 12(100.0)$ \\
\hline GNS-19-01 & CALR & NM_004343.3 & c.1154_1155insTTGTC & p.Lys385AsnfsTer47 & $12 / 12(100.0)$ \\
\hline \multirow[t]{2}{*}{ GNS-19-02 } & NPM1 & NM_002520.6 & c.863_864insCATG & p.Trp288Cysfs*12 & $12 / 14(85.7)$ \\
\hline & NRAS & NM_002524.4 & c. $182 A>G$ & p.Gln61Arg & $15 / 15(100.0)$ \\
\hline GNS-19-03 & JAK2 & NM_004972.3 & c.1849G $>\mathrm{T}$ & p.Val617Phe & $13 / 13(100.0)$ \\
\hline GNS-19-04 & TP53 & NM_000546.5 & c. $833 \mathrm{C}>\mathrm{T}$ & p.Pro278Leu & $18 / 18(100.0)$ \\
\hline \multirow[t]{2}{*}{ GNS-20-01 } & CEBPA & NM_004364.4 & c. $324 C>A$ & p.Tyr108Ter & $14 / 14(100.0)$ \\
\hline & TET2 & NM_001127208.2 & c. $4393 \mathrm{C}>\mathrm{T}$ & p.Arg1465Ter & $15 / 15(100.0)$ \\
\hline \multirow[t]{2}{*}{ GNS-20-02 } & $\mathrm{IDH} 2$ & NM_002168.2 & c. $419 \mathrm{G}>\mathrm{A}$ & p.Arg140Gln & $21 / 21(100.0)$ \\
\hline & NRAS & NM_002524.4 & c. $37 \mathrm{G}>\mathrm{C}$ & p.Gly13Arg & $20 / 20(100.0)$ \\
\hline GNS-20-03 & TP53 & NM_000546.5 & c. $818 \mathrm{G}>\mathrm{A}$ & p.Arg273His & $17 / 17(100.0)$ \\
\hline \multirow[t]{2}{*}{ GNS-20-04 } & $I D H 2$ & NM_002168.2 & c. $419 \mathrm{G}>\mathrm{A}$ & p.Arg140Gln & $19 / 21(90.5)$ \\
\hline & NPM1 & NM_002520.6 & c.860_863dup & p.Trp288CysfsTer12 & 20/21 (95.2) \\
\hline
\end{tabular}

Values are presented as number (\%), unless otherwise stated.

*The acceptance rate is calculated as the number of participants achieving an acceptable result per the total participants. 
위 중 Tier I/II 변이는 각 검체마다 1 개에서 3 개까지 존재하였다.

각각의 의도된 결과로 제시된 변이들에 대한 합격률을 정리하 였다(Table 2). 각 검체마다 참여기관 수가 달랐을 뿐만 아니라 검 체 내에서의 변이마다 참여기관 수가 달라, 한 검체에 대한 합격 률은 산출되지 않았다. 모든 의도된 결과로 제시된 변이에서 $80 \%$ 이상의 합격률을 보였고, 가장 낮은 합격률은 $81.8 \%$ 로 GNS-1802의 CEBPA 유전자에서 관찰된 insertion/deletion variant (INDEL) 변이에서 확인되었다. 총 21 개의 의도된 결과로 제시된 변이 중 14 개에서 $100 \%$ 의 합격률이 확인되었다.

다음으로, 평가에서 제외된 변이가 있는 검체와 해당 변이의 수 를 조사했으며 그 특성과 제외 사유를 정리하였다(Table 3). 전체 12 개의 검체 중 9 개의 검체에서 총 17 개의 평가 제외 변이가 관 찰되었다. 그 중 전자데이터에서 9 개, 핵산 검체에서 8 개가 관찰 되었고, 변이의 유형별로 single nucleotide variant (SNV)는 9 개, INDEL은 8 개가 관찰되었다. 유전자별로는 $A S X L 1, R U N X 1$, $T E T 2$ 에서 각각 3 개씩, CEBPA에서 1 개, 그리고 $B C R, C S F 3 R$,
DNMT3A, KMT2A, MYD88에서 각각 1 개씩 관찰되었다. 평가 제 외 사유로 17 개 변이 모두 참여기관으로부터 $80 \%$ 미만의 합의율 (concordance rate)을 보였으며, 그 중 5 개에서 체세포 변이 분 류에 관한 문제가 있었고, 3 개는 Sanger sequencing 확인검사 상 음성으로 확인되었다. 또한 1 개의 변이는 Sanger sequencing 확인검사상 양성으로 확인되었으나 NGS검사의 검출한계에 근접 한 낮은 변이 대립유전자 빈도를 보이는 변이로 판단되어 평가 제 외되었고, 나머지 1 개의 변이는 NGS검사의 기술적 한계로 인해 검출하기 어려운 위치에서 관찰되는 변이로 확인되어 평가항목에 서 제외되었다.

마지막으로, 'unacceptable'로 평가된 변이가 있는 검체 수와 해당 변이의 수를 조사했으며 해당 변이의 특성과 'unacceptable' 사유를 정리하였다(Table 4). 전체 12 개의 검체 중 5 개의 검체에서 총 9 개의 'unacceptable'로 평가된 변이가 관찰 되었다. 그 중 전자데이터에서 2개, 핵산 검체에서 7 개가 관찰되 었고, 변이의 유형별로 SNV는 3개, INDEL는 6개가 관찰되었다.

Table 3. Non-evaluable variants

\begin{tabular}{|c|c|c|}
\hline Variable & Category & No. \\
\hline No. of specimen with non-evaluable variant & & $9 / 12$ \\
\hline Total no. of non-evaluable variants & & 17 \\
\hline \multicolumn{3}{|l|}{ Characteristics of non-evaluable variants } \\
\hline \multirow[t]{2}{*}{ Data type } & Electronic data & 9 \\
\hline & DNA & 8 \\
\hline \multirow[t]{2}{*}{ Variant type } & Single nucleotide variant & 9 \\
\hline & Insertion/deletion variant & 8 \\
\hline \multirow[t]{9}{*}{ Gene } & ASXL1 & 3 \\
\hline & $R \cup N X 1$ & 3 \\
\hline & TET2 & 3 \\
\hline & CEBPA & 2 \\
\hline & $B C R$ & 1 \\
\hline & CSF3R & 1 \\
\hline & DNMT3A & 1 \\
\hline & KMT2A & 1 \\
\hline & MYD88 & 1 \\
\hline \multirow[t]{5}{*}{ Cause of non-evaluation* } & Concordance rate $<80 \%$ & 17 \\
\hline & Conflict on the variant classification & 5 \\
\hline & Confirmed as false negative & 3 \\
\hline & Low VAF close to the detection limit & 1 \\
\hline & Technical issue of NGS & 1 \\
\hline
\end{tabular}

Abbreviations: VAF, variant allele frequency; NGS, next-generation sequencing. *Duplicate counts were made for the causes of non-evaluable variants. 
Table 4. Unacceptable variants

\begin{tabular}{|c|c|c|}
\hline Variable & Category & No. \\
\hline No. of specimen with unacceptable result & & $5 / 12$ \\
\hline Total no. of unacceptable results & & 9 \\
\hline \multicolumn{3}{|l|}{ Characteristics of unacceptable variants } \\
\hline \multirow[t]{2}{*}{ Data type } & Electronic data & 2 \\
\hline & DNA & 7 \\
\hline \multirow[t]{2}{*}{ Variant type } & Single nucleotide variat & 3 \\
\hline & Insertion/deletion variant & 6 \\
\hline \multirow[t]{4}{*}{ Gene } & NPM1 & 4 \\
\hline & IDH2 & 3 \\
\hline & CEBPA & 1 \\
\hline & IKZFI & 1 \\
\hline \multirow[t]{5}{*}{ Cause of unacceptance* } & Wrong protein numbering & 3 \\
\hline & Wrong nucleotide numbering & 2 \\
\hline & Wrong nucleotide nomenclature format & 2 \\
\hline & False negative & 2 \\
\hline & Transcription error & 2 \\
\hline
\end{tabular}

${ }^{*}$ Duplicate counts were made for the causes of unacceptance.

유전자별로는 NPM1에서 4개, IHD2에서 3개, 그리고 CEBPA와 IKZF1에서 각각 1 개씩 관찰되었다. 'Unacceptable'로 평가된 사 유로는 잘못된 단백질 번호를 입력한 경우가 세 번 관찰되어 가장 많았으며, 잘못된 뉴클레오티드 번호를 입력한 경우, 잘못된 뉴클 레오티드 명명법을 사용한 경우, 위음성으로 보고한 경우 그리고 단순 입력 실수로 인한 경우가 각각 두 번씩 관찰되었다.

\section{고찰}

2018년부터 2020년까지 시행된 NGS-somatic 신빙도조사에 최대 21 개의 기관이 참여하였으며, 그 수가 점점 증가하는 추세를 보이고 있어, 앞으로 신빙도조사 결과 해석에 더욱 강력한 통계적 인 증거가 제공될 것으로 기대된다[7]. 각 검체들에 대한 합격률을 직접 산출할 수는 없었지만, 참여기관들이 각 검사대상 유전체 부 위에서 모두 $80 \%$ 이상의 합격률을 보였고 과반수에서 $100 \%$ 를 달성하였으므로, 체세포 변이와 관련된 NGS검사를 운영하는 국 내 임상검사실의 검사수행능이 우수하다고 판단할 수 있었다.

신뢰도평가는 특정 질환에서 중요한 변이 또는 유전형을 검출 하는 능력을 평가하는 것이므로 신뢰도평가의 의도된 결과로서의 변이는 실제 환자에게서 빈번하고 임상적으로 중요한 변이가 포함 되는 것이 이상적이다[8]. NGS-somatic 신빙도조사에서는 검사
대상 유전체 부위를 혈액종양 환자에게서 임상적으로 중요한 유전 자를 대상으로 하였으며, 검출된 변이들도 대부분 기존에 진단, 치 료 및 예후에 대한 학술적인 근거가 잘 수립되어 있는 변이들로 구 성하였다. 예를 들어, GNS-18-01 검체는 CEBPA, IDH1, NPM1에 서 변이가 관찰되도록 의도되었는데, 세 변이 모두 급성골수성백 혈병 환자에게서 상대적으로 빈번하게 관찰되고 예후와 관련된 것 으로 보고된 바 있다[9-11].

평가에서 제외된 변이와 'unacceptable'로 평가된 변이를 분 석함으로써 실제 체세포 변이 NGS검사 과정에서 발생할 수 있는 몇 가지 유의점들을 확인할 수 있었다. 임상검사실 간 완전히 합의 되지 않은 체세포 변이 분류로 인해 몇몇 변이가 평가에서 제외되 었는데, NGS-somatic 신빙도조사를 통해 향후 임상검사실 사이 의 변이 분류기준을 확립하고 관련된 데이터베이스 구축하는 데 도움을 줄 것으로 생각된다[12]. 또한 평가 제외된 변이 중 확인검 사를 통해 보고하고자 했던 변이가 위음성으로 밝혀지는 경우가 있었으므로, 필요시 임상검사실에서 Sanger sequencing 과 같 은 추가적인 확인검사를 통해 정확한 체세포 변이를 보고할 수 있 도록 권고할 수 있다[3]. 'Unacceptable'로 평가된 변이는 통계적 으로 평가되지 않았지만, 상대적으로 전자데이터보다 핵산 검체 를 대상으로 시행한 신빙도조사에서 'unacceptable'로 평가된 변 이가 빈번하게 발견되었다. 일반적인 신빙도조사는 실험적인 면의 
평가에 초점을 맞추게 되지만, NGS를 활용한 검사의 경우 실험 이 후의 분석단계도 중요하며, 특히 생물정보학적 분석방법이 각 임 상실험실마다 다를 수 있기 때문에 이와 같은 분석방법의 차이로 발생할 수 있는 결과 보고의 오류 등을 확인하여야 한다[1]. 따라 서 NGS-somatic 신빙도조사에서 검체를 전자데이터와 핵산 검 체로 나누어 평가할 수 있도록 하는 방법은 결과 보고까지 복잡한 과정을 수행해야 하는 NGS검사에 필수적인 것으로 생각된다. 이 번 NGS-somatic 신빙도조사의 'unacceptable'로 평가받은 변 이의 사유 대부분이 잘못된 단백질, 뉴클레오티드 번호를 입력하 거나 정확한 뉴클레오티드 번호를 입력하였지만 공식적인 명명법 에 맞지 않는 형식을 사용한 경우였다. 이와 같은 결과를 고려하였 을 때, NGS의 실험단계와 전반적 생물정보학적 분석과정의 오류 는 크게 발견되지는 않았지만, 변이 확인(variant identification) 이후 변이를 명명하는 단계에서 오류가 가장 많이 발생한 것으로 추론할 수 있다. 특히 INDEL 형식의 변이에서 높은 빈도로 뉴클 레오티드 또는 단백질 번호를 잘못 입력하는 경우가 빈번하게 관 찰되었다. 판독자는 NGS 기반의 유전체검사가 실험적인 면과 생 물정보학 면에서 모두 비약적으로 발전했음에도 불구하고 잘못 된 변이가 호출될 가능성이 여전히 존재함을 인식하고, 정렬된 sequence에 대한 시각적 검사를 통하여 부정확한 변이로 의심되 는 부분을 교정하고 필요시 Sanger sequencing과 같은 확인검 사법을 시행함으로써 정확한 체세포 변이 검출 및 보고에 기여할 수 있다[3]. 국내의 생식세포 변이를 검출하기 위한 NGS검사의 신 빙도조사 보고에서는 제시된 RNA reference transcript와 다른 transcript를 사용하는 경우 잘못된 변이의 위치를 기술함으로써 'unacceptable'로 평가되는 변이가 가장 빈번하게 관찰되었으나, 이번 NGS-somatic 신빙도조사에서는 해당 오류는 관찰되지 않 았다[13].

이번 연구의 결과와 같이 신빙도조사에 참여함으로써 임상검사 실은 해당 검사와 관련된 오류를 발견할 수 있고 해결책을 모색하 게 된다. 신빙도조사의 교육적인 효과는 이미 기존 문헌에서 보고 된 바 있으며, 지속적인 신빙도조사 참여를 통한 임상검사실의 검 사수행능 향상이 대규모 연구에서 밝혀진 바 있다. 특히 세 번 이 상 연속적인 신빙도조사를 받은 기관들의 계통적 오류가 대부분 교정되는 것으로 확인되었다[8,14].

본 연구를 통하여 참여기관의 전반적으로 높은 합격률이 확 인되었으나 이는 의도된 결과에 대한 변이만을 대상으로 산출 된 값으로, Tier I/II 변이가 없는 위치를 모두 고려한다면 합격률 이 변동될 수 있다. 대한임상검사정도관리협회에서 제공된 NGSsomatic 신빙도조사 자료를 확인한 결과, 대부분의 기관에서 Tier I/II 변이가 없는 부분에 대한 평가결과를 입력하지 않아 변이 가 없는 위치를 모두 포함한 합격률을 정확히 산출할 수 없었다.
또한 핵산 검체 평가 시 각 참여기관에서 시행하는 검사대상 유전 체 부위에 한해서 보고하도록 하였으므로 각 유전체 부위마다 참 여한 기관의 수의 차이가 발생하고, 이에 따라 각각의 검체에 대 한 전반적인 합격률을 산출하지 못했다. 핵산 검체뿐만 아니라 전 산데이터 평가상에서도 제시된 모든 검사대상 유전체 부위에 대한 평가를 시행하겠다는 기존의 의도와는 달리, 검사대상 유전체 부 위에 참여하는 정도가 임상검사실마다 다르다는 사실이 확인되었 다. 따라서 정확한 합격률을 산출하기 위한 평가방법의 수립 및 안 내가 필요할 것으로 보이며, 이후 산출된 데이터를 분석하여 NGSsomatic 신빙도조사가 각 검사실의 검사수행능의 비교평가 및 향 상정도에 미치는 영향을 구체적으로 판단할 수 있을 것으로 기대 된다.

현재까지 시행되고 있는 NGS-somatic 신빙도조사에서는 참여 기관에게 NGS의 리드 깊이와 대립유전자 빈도를 결과로 입력할 수 있도록 형식을 제공하지만 실제적인 정량적인 평가는 시행되지 않았다. 생식세포의 변이분석과는 달리 실제 체세포의 변이분석에 서는 다양한 분포의 대립유전자 빈도를 보이는 경우가 많고 상대 적으로 낮은 대립유전자 빈도를 측정해야 하는 경우도 빈번하므로 이에 대한 정량평가방법 확립 및 시행이 필요할 것으로 생각된다. 종양 평가를 위한 NGS의 신빙도조사를 실시한 한 보고서에서 각 검사대상 유전체 위치의 리드 깊이 및 대립유전자 빈도뿐만 아니 라 참여기관별 낮은 대립유전자 빈도 값을 이용한 검출한계의 분 포도 조사한 바 있으며 의도된 결과로 제시된 변이에 대한 최소 리 드 깊이도 산출한 바 있다[5].

결론적으로, 2018년부터 2020년까지 대한임상검사정도관리 협회에서 시행한 6 회의 NGS-somatic 신빙도조사의 결과를 분 석함으로써 신빙도조사에 참여한 기관들의 체세포 변이분석을 위 한 NGS검사에 대한 우수한 검사수행능을 확인하였고 앞으로 임 상검사실에서 개선해야할 부분을 제시하였다. 또한 신빙도검사 를 더욱 효과적으로 실시하기 위한 방안들이 논의되었으며, NGSsomatic 신빙도조사를 지속적으로 수행함으로써 임상검사실의 검사수행능 향상에 기여할 것으로 생각된다.

\section{ORCID}

Hongkyung Kim https://orcid.org/0000-0003-4185-1672 Dongju Won Saeam Shin Seung-Tae Lee https://orcid.org/0000-0002-0084-0216 https://orcid.org/0000-0003-1501-3923 Jong Rak Choi https://orcid.org/0000-0003-1047-1415 https://orcid.org/0000-0002-0608-2989 


\section{REFERENCES}

1. Zhong Q, Wagner U, Kurt H, Molinari F, Cathomas G, Komminoth P, et al. Multi-laboratory proficiency testing of clinical cancer genomic profiling by next-generation sequencing. Pathol Res Pract 2018;214:957-63.

2. Pereira B, Chin SF, Rueda OM, Vollan HK, Provenzano E, Bardwell HA, et al. The somatic mutation profiles of 2,433 breast cancers refines their genomic and transcriptomic landscapes. Nat Commun 2016;7:11479.

3. Bacher U, Shumilov E, Flach J, Porret N, Joncourt R, Wiedemann G, et al. Challenges in the introduction of nextgeneration sequencing (NGS) for diagnostics of myeloid malignancies into clinical routine use. Blood Cancer J 2018;8:113.

4. Segal JP. Next-generation proficiency testing. J Mol Diagn 2016;18:469-70.

5. Merker JD, Devereaux K, lafrate AJ, Kamel-Reid S, Kim AS, Moncur JT, et al. Proficiency testing of standardized samples shows very high interlaboratory agreement for clinical next-generation sequencing-based oncology assays. Arch Pathol Lab Med 2019;143:463-71.

6. Schrijver I, Aziz N, Jennings LJ, Richards CS, Voelkerding KV, Weck KE. Methods-based proficiency testing in molecular genetic pathology. J Mol Diagn 2014;16:283-7.

7. Belli M, Ellison SL, Fajgelj A, Kuselman I, Sansone U, Wegscheider W. Implementation of proficiency testing schemes for a limited number of participants. Accredit Qual Assur 2007;12:391-8.

8. Kalman LV, Lubin IM, Barker S, du Sart D, Elles R, Grody WW, et al. Current landscape and new paradigms of proficiency testing and external quality assessment for molecular genetics. Arch Pathol Lab Med 2013;137:983-8.

9. Rau R, Brown P. Nucleophosmin (NPM1) mutations in adult and childhood acute myeloid leukaemia: towards definition of a new leukaemia entity. Hematol Oncol 2009;27:171-81.

10. Preudhomme C, Sagot C, Boissel N, Cayuela JM, Tigaud I, de Botton S, et al. Favorable prognostic significance of CEBPA mutations in patients with de novo acute myeloid leukemia: a study from the Acute Leukemia French Association (ALFA). Blood 2002;100:2717-23.

11. DiNardo CD, Ravandi F, Agresta S, Konopleva M, Takahashi K, Kadia T, et al. Characteristics, clinical outcome, and prognostic significance of IDH mutations in AML. Am J Hematol 2015;90:732-6.

12. Wagner AH, Walsh B, Mayfield G, Tamborero D, Sonkin D, Krysiak K, et al. A harmonized meta-knowledgebase of clinical interpretations of somatic genomic variants in cancer. Nat Genet 2020;52:448-57.

13. Seong MW, Kim M, Shin HS, Cho SI, Park SS. Three-year experience of an external proficiency testing survey for nextgeneration sequencing-based testing for germline mutation. Lab Med Qual Assur 2020;42:48-53.

14. Hoeltge GA, Phillips MG, Styer PE, Mockridge P. Detection and correction of systematic laboratory problems by analysis of clustered proficiency testing failures. Arch Pathol Lab Med 2005;129:186-9. 